\title{
Project selection frameworks and methodologies for reducing risks in project portfolio management
}

\author{
Fabio Nonino \\ Sapienza University of Roma, Italy
}

\begin{abstract}
Extracting and consolidating knowledge from past projects can help managers in selecting projects with the correct level of riskiness, while market analysis gives directions for reaching the objective of a balanced project portfolio. To this extent, the chapter discusses strategic importance of project selection and the role of risks and uncertainties in project portfolio management and presents different some fundamental and innovative frameworks and project selection methodologies for balancing risks. Finally, the chapter proposes a model containing an innovative methodology, based on artificial neural networks, to help managers in balancing project portfolio and assessing projects during the selection phase on the basis of risks, uncertainties and critical success factors.
\end{abstract}

Keywords: Project selection, Balanced portfolio, Project portfolio risk management

\section{INTRODUCTION}

Project portfolio management (PPM) extends the objective of realizing successful projects to the alignment with strategic business objectives, but expected project success still remains the main determinant for projects selection. But management knows it and so do project managers: selection of new projects cannot be based only on quasi-guaranteed short-term revenues as the year-to-year viability of a company depends on its ability to innovate, the uncertain long-term returns on the company's total innovation investment.

The contemporary competitive environment, with its widespread lack of information, misleading signs and difficulties in forecasting future scenarios, makes the investments in the acquisition and management of projects always riskier. Consequently, one of the objectives of manager is the assessment of risk across project portfolio. Companies must learn to manage innovation strategically to achieve a competitive advantage through a well-balanced portfolio. But what does it mean to balance a project portfolio?

As regard new markets and innovative products, firms should construct a portfolio selecting projects that balance riskiness of long-term return of investment for projects that will become the engines of blockbuster growth with guaranteed short-term revenues. Therefore, companies should align project portfolio with their strategic business objectives, achieving maximal project portfolio value by combining performances of projects in order to maximize the shareholders' value while balancing resource allocation and risks (Costantino et al., 2015). 
Achieving maximal project portfolio value for the resources used is often complicated by multiple selection criteria, subjective and imprecise assessments and project interdependencies. Project critical success factors (PCSFs) can serve as manageable criteria to prevent possible causes of failures with an effective project selection process, taking into account company strategic objectives, project manager's experience and the competitive environment.

The first section discusses strategic importance of project selection and the role of risks and uncertainties in project portfolio management. The subsequent section examines some fundamental and innovative frameworks and project selection methodologies for balancing project portfolio risks. The last part of the chapter proposes a framework an innovative methodology to help managers in assessing projects during the selection phase. An artificial neural network (ANN), scalable to any set of PCSFs, classifies the level of project's riskiness by extracting the experience of project managers from a set of past successful and unsuccessful projects taking into account risks and uncertainties.

\section{RISKS AND UNCERTAINTIES IN PROJECT PORTFOLIO SELECTION}

The main objectives of the project portfolio management are the identification, the ranking, the prioritization, the selection and the authorization of projects or programs. Project selection is a strategic process aimed at evaluating individual projects or groups of projects and then choosing which implement so that the objectives of the parent organization are achieved (Meredith et al., 2015). However, too often it fails (Ghapanchi et al., 2012) due to complexity caused by many factors, exogenous and endogenous, such as uncertainty, interrelationships among projects, changes over time and stakeholders behaviour. Project portfolio selection is the result of multiple and conflicting objectives. The first challenge in managing project portfolio is translate qualitative objectives in measurable and manageable quantitative goals. The second is to identify the interdependence of projects driven by common objectives and often scarce resources. The third is managing risk and uncertainties while balancing revenues and investments, reaching the so-called ambidexterity, i.e. exploitation of consolidated products/services and standardized processes vs. exploration of new business opportunities.

The process of protection from risks and uncertainties represents a fundamental component of the project portfolio and project management activities and needs of models, frameworks and methodologies translated in systematic procedures. Managers can reach a proper control of the projects' portfolio, balancing the overall exposure to risks, only with a clear perception of the expected results on every single project; in this context, risk analysis can help project managers to handle a portfolio of projects with different characteristics (Costantino et al., 2015).

Project Risk Management supports managerial and organizational control (Söderlund, 2004) to minimize criticalities by identifying potential risks and correct responses to avoid project failure due to shifts and gaps from the target values. Nevertheless, leveling up the complexity grows. For instance, at project portfolio level risk management should takes into account interdependencies regarding resources, knowledge, and strategy (Sanchez et al., 2008). Furthermore, in cases where resource limitations are at fault for failing projects, a project selection model that incorporated the risk of resource limitations could have aided the decision maker in avoiding such mistakes (Schniederjans and Santhanam, 1993).

\section{Which are risks in project portfolio management?}

Project portfolio risk management is essential in any industry. As asserted by Abbasianjahromi and Rajaie (2012), portfolio management of construction project requires taking into account the risks, which are inherent in the industry. Especially in the project selection phase is inevitable. Also BPR projects, due to their nature, require a careful management of risks which can be categorized in three general groups of "business", "financial" and "organization" in which organizational risk - consisting of four dimensions of structure, culture, technology and human resource - plays a critical role in the associated risk of BPR (Remenyi and Heafield, 1996). As regards R\&D portfolio management, the research by Floricel and 
Ibanescu (2008) shows that high-velocity environments favor structured as well as integrated portfolio management approaches, while high-growth environments favor approaches that are structured, but commit significant resources to each project as well.

Risk management at the project level is more important for R\&D-dominated project portfolios, whereas the integration of risk information is more important with high levels of turbulence and portfolio dynamics (Teller et al., 2014).

As a matter of fact, risks are dynamics because of the environmental changes. Consequently, companies should face these changes by adapting portfolio management processes to competitive context that change more or less rapidly. Floricel and Ibanescu (2008) suggest that the level of dynamism of risks depends on the following patterns of environmental dynamics:

- Velocity: advances in the frontier of functionality, performance and cost brought about by technological innovation.

- Turbulence: the extent of perceived discontinuity in environmental change with respect to past trends and anticipated directions.

- Growth: the perception of increasing resource inflows.

- Instability: the perception of a steady and diverse array of competitive moves by other strategic actors, such as product imitation and promotional wars, and from competitors entering with cheap or substitute products.

\section{Risks or uncertainties?}

As well-known by project managers and team members, risk is a combination of the probability of an event (with a desirable and undesirable occurrence) and the consequences associated with that event.

Project risk management requires the identification and the estimation of probability of occurrence and impacts of risks associated to the project activities. Information used in estimating risk can be derived from expert opinion, technical data, or previous experience with similar projects (Archer and Ghasemzadeh, 1999).

The most advanced companies estimate overall risks in the project portfolio using models which combine the risks of each activity, including interdependent events and resources. Models used in analyzing risk include Monte Carlo simulation, decision theory and Bayesian statistical theory. However, these techniques are not widely used because they are too complex and require too much input data, they provide an inadequate treatment of risk and uncertainty, they fail to recognize interrelationships and interrelated criteria, they may just be too difficult to understand and use, or they may not be used in the form of an organized process (Cooper, 1993). As project managers know, in the majority of projects a significant level of complexity affects project life cycle and different sources of risk influence its success (Cagno et al., 2007):

- indeterminateness, ambiguity or poor definition and sharing of targets;

- lack or low measurability of targets and a consequent low capability of evaluating and recognize performances;

- inadequate resource allocation, i.e. right resources but wrongly managed or insufficient resources due to a wrong estimation;

- incorrect and not detailed identification of all the customer's and company's requirements;

- fast evolving markets and industries with a continuous need of targets re-alignment and replanning;

- inaccurate planning or errors in implementation of project management processes.

Nevertheless, in current competitive context uncertainty is increasing day by day and managers take strategic decisions on project portfolio (like a tender's participation or a project authorization) under non- 
deterministic conditions which are source of risks. Some scholars and practitioners have encouraged the use of the broader concept of uncertainty management instead of risk management (Petit, 2012).

Uncertainty management implies exploring and understanding the sources of project risks. The focus is on the inputs (external and internal resources, market and organizational dynamics, evolution of financial markets...) that could affect projects rather than on the project activities. From PPM perspective, this means to discover and to proactively manage factors and resources with create high variability in organizational activities outside individual project contexts that have impacts on a number of projects. This perspective highlights the need to put in place different approaches and techniques to address some aspects of project related uncertainty.

Generally, project uncertainty comes from technical, market, organization or financial factors. Operationalization of uncertainty concept and its use in PPM is a practice still in its infancy. Some authors (e.g. Huang, 2010; Huang, 2011; Huang, 2012; Huang and Qiao, 2012 and Huang and Ying, 2013) introduced uncertainty theory to portfolio selection using experts' estimation rather than historical data, an uncertain risk curve and an uncertain risk index. Petit (2012) showed how to map certainties and uncertainties using five dimension: technical, market, organizational, financial and norms and regulations. Table 1 reports sources of uncertainty in four portfolio studied by the author.

Table 1. Mapping of the sources of uncertainty (source: Petit, 2012).

\begin{tabular}{|c|c|c|c|c|}
\hline & Soft1 & Soft2 & Fin1 & Fin2 \\
\hline \multirow[t]{2}{*}{ Technical } & 3rd party product & 3rd party product & & \\
\hline & Technology & Technology & & \\
\hline \multirow[t]{5}{*}{ Market } & $\begin{array}{l}\text { Match product with } \\
\text { customers' needs }\end{array}$ & $\begin{array}{l}\text { Match product with } \\
\text { customer needs }\end{array}$ & $\begin{array}{l}\text { Match product with } \\
\text { customer needs }\end{array}$ & $\begin{array}{l}\text { Match product with } \\
\text { customer needs }\end{array}$ \\
\hline & $\begin{array}{l}\text { Competitor's } \\
\text { offering }\end{array}$ & Competitor's offering & & \\
\hline & New customers & & & \\
\hline & New market & & & \\
\hline & New applications & & & \\
\hline Organizational & & & $\begin{array}{l}\text { Availability of } \\
\text { resources }\end{array}$ & $\begin{array}{l}\text { Availability of } \\
\text { resources }\end{array}$ \\
\hline Financial & & Funding structure & & \\
\hline \multirow[t]{2}{*}{$\begin{array}{l}\text { Norms and } \\
\text { regulations }\end{array}$} & & & $\begin{array}{l}\text { Content of Basel } \\
\text { agreement }\end{array}$ & $\begin{array}{l}\text { Content of new } \\
\text { accounting } \\
\text { regulations }\end{array}$ \\
\hline & & & $\begin{array}{l}\text { Interpretation of } \\
\text { Basel agreement }\end{array}$ & $\begin{array}{l}\text { interpretation of new } \\
\text { accounting } \\
\text { regulations }\end{array}$ \\
\hline
\end{tabular}

\section{Critical success factor as drivers for project selection}

An early evaluation of the expected success of projects is a very tough process so organizations should set up tools and methods that could help managers to forecast performances. Risk of projects' failure is different from risk of project management failure. Companies' managers should be aware about the difference between project success, that measures the achievement of the overall objectives, and project management success, that measures the performance of the management process. Project success is next to the idea of effectiveness (achieved vs. targeted objectives) while project management success is next to the idea of efficiency (consumed resources vs. achieved targets). Project management is only one of the many factors that can influence the success or the failure of a project like, for example, organizational structure, size of the project, industrial sector, different perspectives of the stakeholders, different stages of the life cycle (Turner and Müller, 2005). 
Project critical success factors (PCSFs) are those governable factors that increase the ability of organizations to carry a project through its full implementation and which allows managers to set the operative priorities and determine the actions that can drive towards success. Consequently, organization must drive factors to reduce the risk of project failure.

A useful knowledge base is the project implementation profile (PIP), developed Slevin and Pinto in 1986 and tested in different PM context (Pinto, 1990), contains ten critical factors crucial for the implementation of a successful project (see Table 2).

Table 2. The ten key factors of the project implementation profile (source: Slevin and Pinto, 1986).

\begin{tabular}{|l|l|}
\hline \multicolumn{1}{|c|}{ Factors } & \multicolumn{1}{c|}{ Definition } \\
\hline Project mission & Initial clearly defined goals and general directions. \\
\hline $\begin{array}{l}\text { Top management } \\
\text { support }\end{array}$ & $\begin{array}{l}\text { Willingness of the top management to provide the necessary } \\
\text { resources and authority/power for project success. }\end{array}$ \\
\hline Project schedule/plan & $\begin{array}{l}\text { A detailed specification of the individual actions steps for project } \\
\text { implementation. }\end{array}$ \\
\hline Client consultation & $\begin{array}{l}\text { Communication, consultation, and active listening to all } \\
\text { impacted parties. }\end{array}$ \\
\hline Personnel & $\begin{array}{l}\text { Recruitment, selection, and training of the necessary personnel } \\
\text { for the project team. }\end{array}$ \\
\hline Technical tasks & $\begin{array}{l}\text { Availability of the required technology and expertise to } \\
\text { accomplish the specific technical action steps. }\end{array}$ \\
\hline Client acceptance & \begin{tabular}{l} 
The act of "selling" the final project to its ultimate intended users. \\
\hline $\begin{array}{l}\text { Monitoring and } \\
\text { feedback }\end{array}$
\end{tabular}$\quad \begin{array}{l}\text { Timely provision of the comprehensive control information at } \\
\text { each stage in the implementation process. }\end{array}$ \\
\hline Communication & $\begin{array}{l}\text { The provision of an appropriate network and necessary data to all } \\
\text { key actors in the project implementation. }\end{array}$ \\
\hline Troubleshooting & Ability to handle unexpected crises and deviations from plan. \\
\hline
\end{tabular}

Among the several studies which verified and discusses the PIP, the research of Cooke-Davies (2002) analyzed 136 projects (by 23 organizations) obtaining 12 CSFs partially overlapping PIP and explicitly considering four CSFs related to risk management: company-wide education on risk management, organization's processes for assigning ownership of risks, risk register, up-to-date risk management plan.

\section{BALANCING RISKS ACROSS PROJECT PORTFOLIO}

Balancing the portfolio in terms of risk and time to complete because companies does not want too much investment in high risk or long term projects (Ghasemzadeh and Archer, 2000) because an overcommitment to high risk projects may jeopardize the future of the organization (Cooper, 1993).

Cooper et al. $(1997,2001)$ recognized that balancing the diversification of the projects in the portfolio in terms of various tradeoffs, such as high risk versus sure profits or make or buy, should be an objective of PPM as much as the alignment of the mix of projects in the portfolio with the strategic goals of the organization or the value of the portfolio in terms of long-term profitability, return-on-investment and likelihood of success. 
Even if the Standard for Portfolio Management published by PMI addresses portfolio risk management and provides guidelines for integrating risk management into project portfolio management, only a few frameworks and methodologies have been developed that integrate risk management into project portfolio management (Teller et al., 2014.). Below some of the most important frameworks and methodologies are described.

\section{Frameworks for balancing risk across project portfolio}

The classic strengths, weaknesses, opportunities, and threats (SWOT) analysis can be a fruitful method for identifying potential projects. A first advantage of this framework is that forces company's leaders to explicitly consider risks (Kloppenborg and Laning, 2012). Moreover, having a clear identification of threats and opportunities that can arise, and evaluating any possible alternative in terms of project sustainability (Ghosh and Jintanapakanont, 2004), allows companies containing the level of uncertainty and setting up the risk identification.

An interesting framework in which risk is considered as a balancing between new projects' exploration and products' exploitation, is the Innovation Ambition Matrix (Nagji and Tuff, 2012), a refinement of the classic Ansoff's matrix. It is a useful PPM tool for suggesting how selecting projects among growth initiatives in line with company's strategy. The matrix (Figure 1) replaces Ansoff's binary choices of product and market (old versus new) with a range of values: novelty degree of a company's offerings (on the $\mathrm{x}$ axis) and novelty degree of its customer markets (on the y axis).

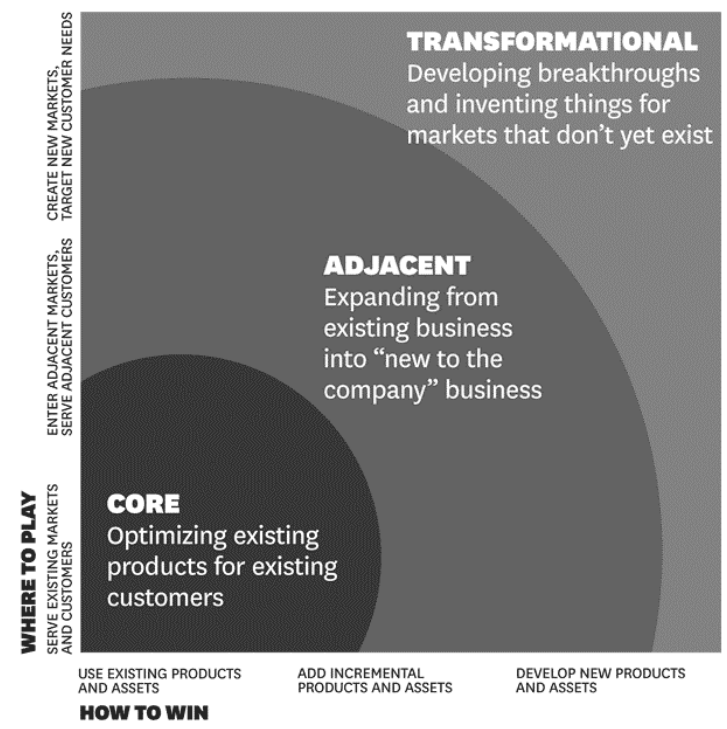

Figure 1. Innovation Ambition Matrix (source: Nagji and Tuff, 2012)

Nagji and Tuff suggest that firms that excel at total innovation management simultaneously invest at three levels of ambition:

- in the band of activity at the lower left of the matrix are core innovation initiatives which correspond to incremental changes to existing products and incremental inroads into new markets;

- in the band of activity at the upper right are transformational initiatives, which correspond to disruptive products designed to create new offers and to serve new markets and customer needs;

- in the middle are adjacent innovations, which can share characteristics with core and transformational innovations, which correspond to leverage existing capabilities but necessitate putting those capabilities to new products. 
The research of Nagji and Tuff shows that companies that allocated about $70 \%$ of their innovation activity to core initiatives, $20 \%$ to adjacent ones, and $10 \%$ to transformational ones outperformed their peers. Of course some contextual factors change the proportion of investments on the three initiatives: typology of industry, company's competitive position and company's stage of development.

The analysis of industry impact could be conducted using the classic industry attractiveness - business strength matrix (Figure 2).

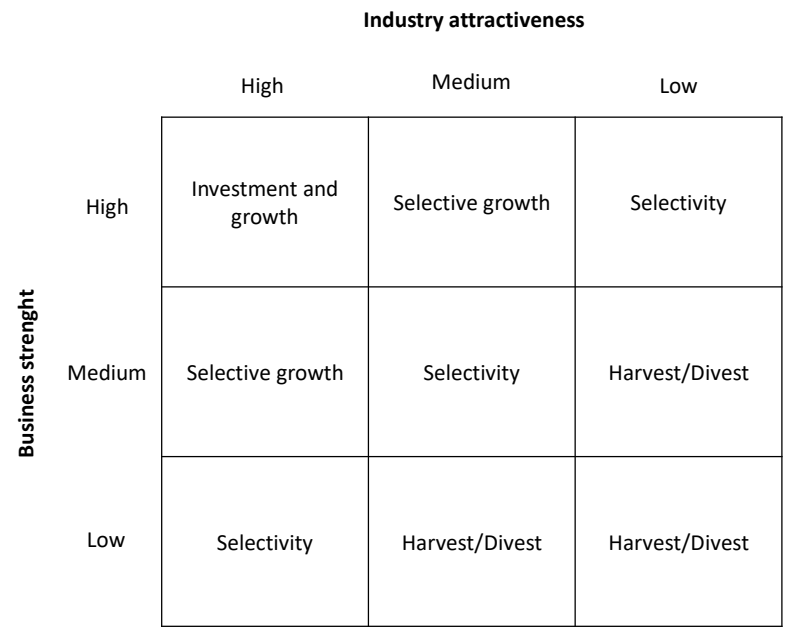

Figure 2. Industry attractiveness - business strength matrix (proposed by Lin and Hsieh, 2004 from Hax and Majluf, 1983)

As suggested by Lin and Hsieh (2004), the classic GE Multifactor Portfolio Matrix, firstly developed by Hax and Majluf in 1983, could be used to help managers to better understand the competitive position of strategic business units (SBUs) based primarily on industry attractiveness, driven by external and uncontrollable factors, and business strength, based on the critical success factors, which is largely controllable by the firm.

Day (2007) proposes a modified version of the classic risk matrix (Figure 3). Each project is placed on the matrix by determining its score on two dimensions: the familiarity of the company to the intended market (x axis) and to the product or technology (y axis).

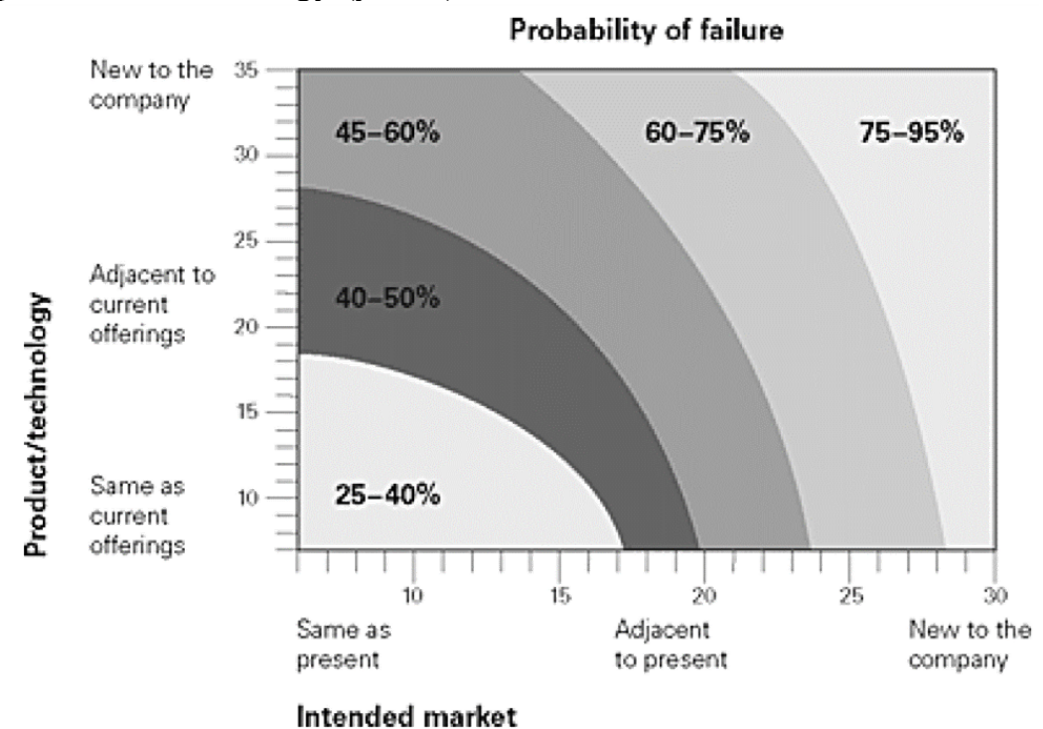

Figure 3. Risk Matrix (Source: Day, 2007) 
Riskier projects, i.e. with high probability of failure, are in the upper right. The probability of failure should be estimated by analyzing the market and industry through a representative number of interviews. Portfolio managers should posit companies' projects on the risk matrix on the basis of project characteristics. The projects can be represented with a circle and the length of diameter could be proportional to the project's estimated revenue, the estimated investment or absorption of scarce resources.

Another framework, born in the context of project portfolio management is risk-reward bubble diagram. In basic and most popular diagram (Figure 4), the probability of technical success of projects is assigned to the vertical axis while net present values are assigned to the horizontal axis (Moustafaev, 2010). Circles represent projects, their area is proportional to the project size while the color of each circle could denote the program or the product typology. Projects belonging to the four quadrants have different names: oysters, pearls, white elephants and bread and butter.

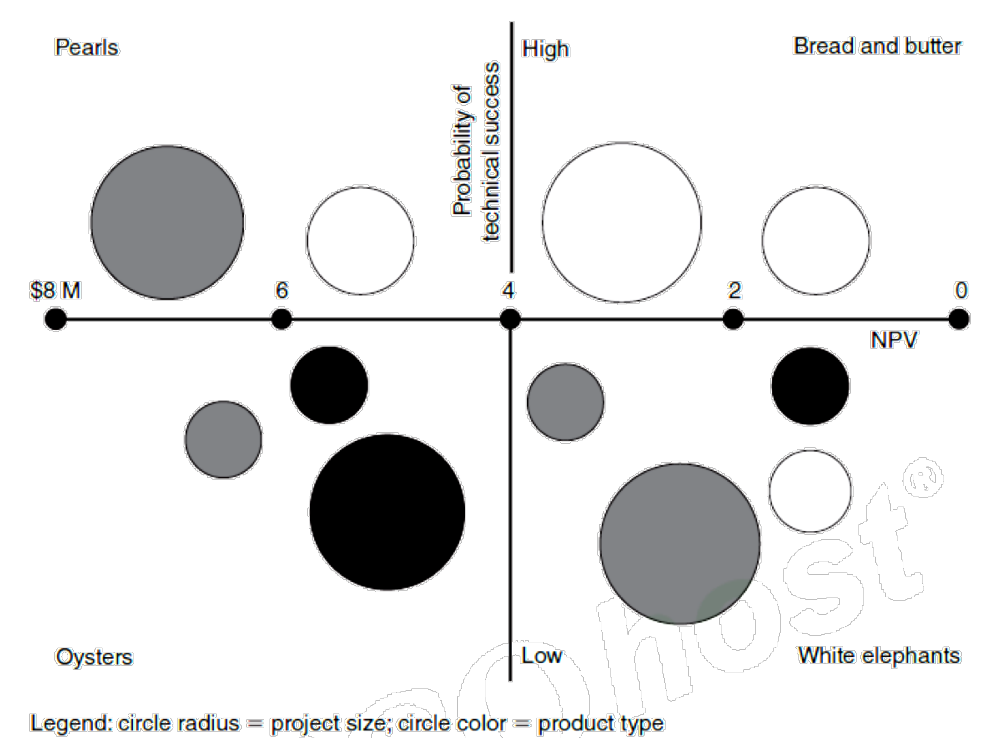

Figure 4. Risk-reward bubble diagram (source: Moustafaev, 2010)

As already discussed before, companies should select and initiate, on average, pearl projects, the core initiatives, for about $70 \%$ of their resources, and a $10 \%$ of oyster projects, the transformational ones, considering an absorption of the $10 \%$ of capabilities. Adjacent projects are between pearl and oyster projects.

As reported by Cooper et al. (2002) fifteen years ago, the most popular bubble diagram among companies was Risk vs. Reward chart, where risk was considered a measure of probability of success. Nevertheless, companies considered also other bubble diagrams as reported in Table 3.

Table 3. Popular Bubble diagrams plot - rank ordered by popularity (source Cooper et al., 2002)

\begin{tabular}{|c|c|c|c|c|}
\hline Rank & Type of chart & First dimension plotted & & Second dimension plotted \\
\hline 1 & Risk vs. Reward & $\begin{array}{l}\text { Reward: NPV, IRR, } \\
\text { benefits after years of } \\
\text { launch, market value }\end{array}$ & by & $\begin{array}{l}\text { Probability of success } \\
\text { (technical, commercial, } \\
\text { overall) }\end{array}$ \\
\hline 2 & Newness & Technical newness & by & Market newness \\
\hline
\end{tabular}




\begin{tabular}{|c|l|l|r|l|}
\hline 3 & Ease vs. Attractiveness & Technical feasibility & by & $\begin{array}{l}\text { Market attractiveness (growth, } \\
\text { potential, consumer appeal, life } \\
\text { cycle) }\end{array}$ \\
\hline 4 & Strength vs. Attractiveness & $\begin{array}{l}\text { Competitive position } \\
\text { (strengths) }\end{array}$ & by & $\begin{array}{l}\text { Attractiveness (market growth, } \\
\text { technical maturity, years to } \\
\text { implementation) }\end{array}$ \\
\hline 5 & Cost vs. Timing & Cost to implement & by & Time to implement \\
\hline 6 & Strategic vs. Benefit & Strategic focus or fit & by & $\begin{array}{l}\text { Business intent, NPV, financial } \\
\text { fit, attractiveness }\end{array}$ \\
\hline 7 & Cost vs. Benefit & Cumulative reward & by & Cumulative development costs \\
\hline
\end{tabular}

Bubble diagram in figure 5, used by $3 \mathrm{M}$ and reported by Cooper et al. (2002), aims to deal with environmental uncertainties by considering probability of development and scale up success vs. NPV with optimistic and pessimistic estimates. The size and shape of the bubble measure the uncertainty of projects: large bubbles reveal projects with high uncertainty in both dimensions, small bubbles reveal projects with low uncertainty.

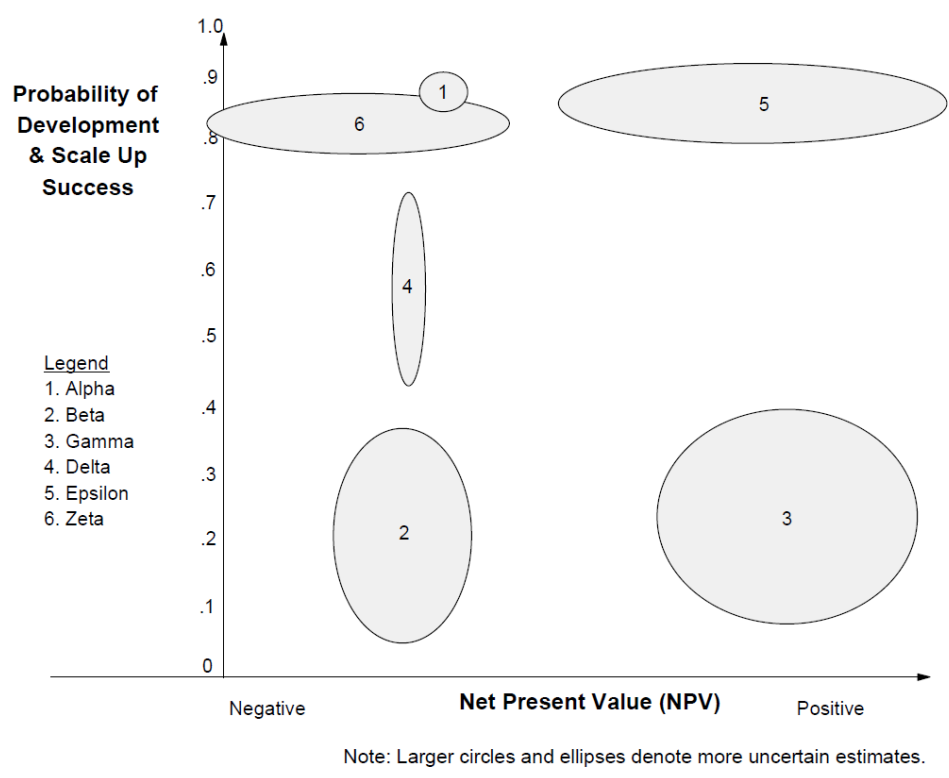

Figure 5. 3M's Risk-reward bubble diagram showing uncertainties (source: Cooper et al., 2002)

As will be reported in the next paragraph, the most advanced project selection methodologies use multicriteria scoring involving particular optimization algorithms. Managerial frameworks for the project prioritization on the basis of multiple selection criteria taking into account risks and resource constraints, are the so-called Project/Program evaluation matrices. For instance, a format for the project evaluation matrix is shown in the simplified example proposed by Kloppenborg and Laning (2012) in Table 4. In this example companies utilize three information to determine the "value/risk efficiency frontier" with regard to available capital:

- The forecast capital needs of the project in the budget year. 
- The weighted strategic value of each project.

- The weighted strategic risk of deferring each project.

Table 4. Simplified value/risk project portfolio optimization model (source: Kloppenborg and Laning, 2012)

\begin{tabular}{|c|c|c|c|c|c|c|c|c|c|c|c|c|c|c|}
\hline \multirow{4}{*}{$\begin{array}{c}\text { Project } \\
\text { description }\end{array}$} & \multirow{4}{*}{ 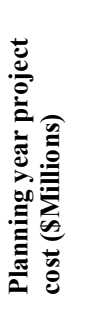 } & & Pro & ect va & & & \multirow{4}{*}{ 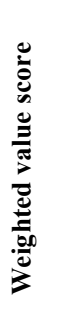 } & \multirow{2}{*}{\multicolumn{5}{|c|}{$\frac{\text { Project Deferral risk }}{\text { Strategy areas and weighting }}$}} & \multirow{4}{*}{ 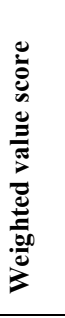 } & \multirow{4}{*}{ 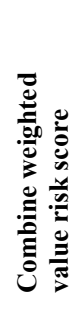 } \\
\hline & & \multicolumn{5}{|c|}{ Strategy areas and weighting } & & & & & & & & \\
\hline & & 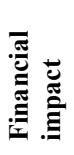 & 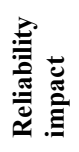 & 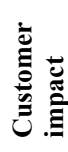 & 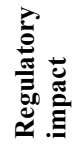 & 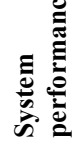 & & 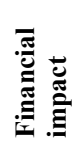 & 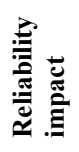 & 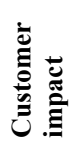 & 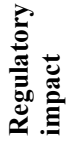 & 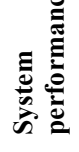 & & \\
\hline & & $40 \%$ & $20 \%$ & $20 \%$ & $10 \%$ & $10 \%$ & & $40 \%$ & $20 \%$ & $20 \%$ & $10 \%$ & $10 \%$ & & \\
\hline Project A & $\$ 5.50$ & 7 & 7 & 7 & 2 & 4 & 6.20 & 7 & 7 & 7 & 9 & 4 & 6.90 & 13.10 \\
\hline Project B & $\$ 10.00$ & 4 & 8 & 3 & 8 & 8 & 5.40 & 9 & 8 & 3 & 8 & 8 & 7.40 & 12.80 \\
\hline Project C & $\$ 16.40$ & 8 & 1 & 3 & 5 & 5 & 5.00 & 5 & 4 & 3 & 5 & 5 & 4.40 & 9.40 \\
\hline Project D & $\$ 3.00$ & 2 & 4 & 5 & 8 & 5 & 3.90 & 8 & 4 & 6 & 4 & 5 & 6.10 & 10.00 \\
\hline Project E & $\$ 16.90$ & 9 & 1 & 5 & 5 & 5 & 5.80 & 5 & 3 & 6 & 5 & 6 & 4.90 & 10.70 \\
\hline Project F & $\$ 9.00$ & 2 & 6 & 9 & 9 & 9 & 5.60 & 7 & 7 & 10 & 9 & 9 & 8.00 & 13.60 \\
\hline $\begin{array}{l}\text { Planning year } \\
\text { budget limit }\end{array}$ & $\$ 25.00$ & & & & & & & & & & & & & \\
\hline $\begin{array}{l}\text { Selected project } \\
\text { spend forecast }\end{array}$ & $\$ 24.50$ & & & & & & & & & & & & & \\
\hline
\end{tabular}

\section{Risk-based project selection methodologies}

In the project portfolio management, the gathering of possible projects, their prioritization and selection usually involve particular optimization algorithms or management techniques that make use of specific project selection criteria (Kaiser et al., 2015). Project selection approaches can be distinguished between financial and non-financial models while project selection methodologies range from single criteria costbenefit analysis to multi-criteria scoring and ranking methods, or subjective evaluation methods.

As regards financial models, researchers proposed also selection model for investment decisions based on risks where discount rates usually act as a risk measurement indicator (e.g. WACC) and profitability indicators (e.g. NPV, IRR, benefits after years of launch, market value) act as objectives. Jafarizadeh and Ramazani Khorshid-Doust (2008) considered as principal selection criteria the semi-deviation of return, i.e. the measure of risk of projects that is more consistent with the definition of risk as the probability of unwanted outcomes.

A relevant instrument for valuing information technology (IT) investments and prioritizing a portfolio of projects is the real options analysis (Bardhan et al., 2004). Real options can start from real data on expected project benefits and costs in different scenarios to calculate the option value of all projects considering also budget constraints. Bardhan et al. (2010) developed a prioritization approach to integrate real option analysis with a software project portfolio optimization model; their approach is focused on information technology portfolio risk management and can helps managers to make effective decisions, such as for investments in a service-oriented architecture, to enable flexible IT capabilities and shows the importance of balancing project-specific risks with the potential value derived across a multiperiod horizon.

The literature presents a number of studies addressing project selection using multi-criteria scoring adopting different methodologies: fuzzy decision support system, genetic algorithm-based multi-criteria, 
multi-objective particle swarm optimization for project selection problem, Data Envelopment Analysis and analytic network process. Moreover, also simplified simulation model are proposed.

Abbasianjahromi and Rajaie (2012) proposed a model which attempts to optimize project selection based on the endurable risk level of a company with regard to the existing portfolio applying the fuzzy multi criteria decision-making approaches. Hall et al. (2015) considered a project selection problem where each project has an uncertain return with partially characterized probability distribution; to model and evaluate this risk, they proposed and justify a general performance measure, the underperformance riskiness index (URI) and defined a special case of the URI, the entropic underperformance riskiness index (EURI), for the project selection problem. Eilat et al. (2006) proposed a DEA based methodology for constructing and valuating balanced portfolios of R\&D projects using three indices, risk, efficiency and balance: (1) the risk index for a project is the product of the projects overall budget and the probability that the project will not succeed. (2) the efficiency index for a project is the efficiency score computed by the CCR model and (3) the balance index for a project is computed as a ratio of the DEA - BSC score and the CCR score of that project.

Also Artificial Neural Networks (ANNs) can be used to create a project selection model able to "learn" the knowledge from historical project selection. Artificial neural network model is a non-parametric method, therefore it is superior in the ranking and the selection of projects compared to regression analysis, that is a parametric method (Olanrewaju et al., 2011). In the following paragraph a framework for balancing risks based an artificial neural network model is proposed.

\section{A FRAMEWORK FOR BALANCING PROJECT PORTFOLIO RISKS BASED AN ARTIFICIAL NEURAL NETWORK MODEL}

The model for early assessment of project success is based on critical success factors of project implementation using Artificial Neural Network (ANN) and it is the result of a research conducted by Costantino et al. (2015) and tested on data coming from 150 project of a leader Italian EPC contractor. The three main advantages of artificial neural networks in project selection are:

1. ease of use because ANN extracts implicit knowledge from past experience without involving managers in complex and fallible judgements;

2. applicability to any industry, project types, and company because customizable to any critical success factors framework;

3. dynamic learning capacity of ANN models which can allow a review of project evaluation during the project lifecycle.

Figure 6 shows how a company can use the ANN assessment model in the project selection and the two "learning processes" of the model. The enterprise environmental factors and knowledge gained in previous projects, the organizational process assets, are crucial for identifying and preparing accurate and viable tenders starting from the project statement of work (SOW) and, subsequently, the business case.

In the model, risks are considered inside project portfolio selection process and inside the individual project analysis. Companies start from risk balance analysis using one of the strategic framework proposed in the previous paragraph. This requires a strategic definition of certain portfolio dimensions, such as novelty degree of project vs novelty degree of its customer for the Innovation Ambition Matrix or probability of technical success of projects vs net present value for the Risk-reward Bubble Diagram. These information are fundamental for both selecting project and both updating critical success factors. The model requires also a statement of project critical success factors. However, managers can use the previous experience to define or to re-define project PCFSs. 


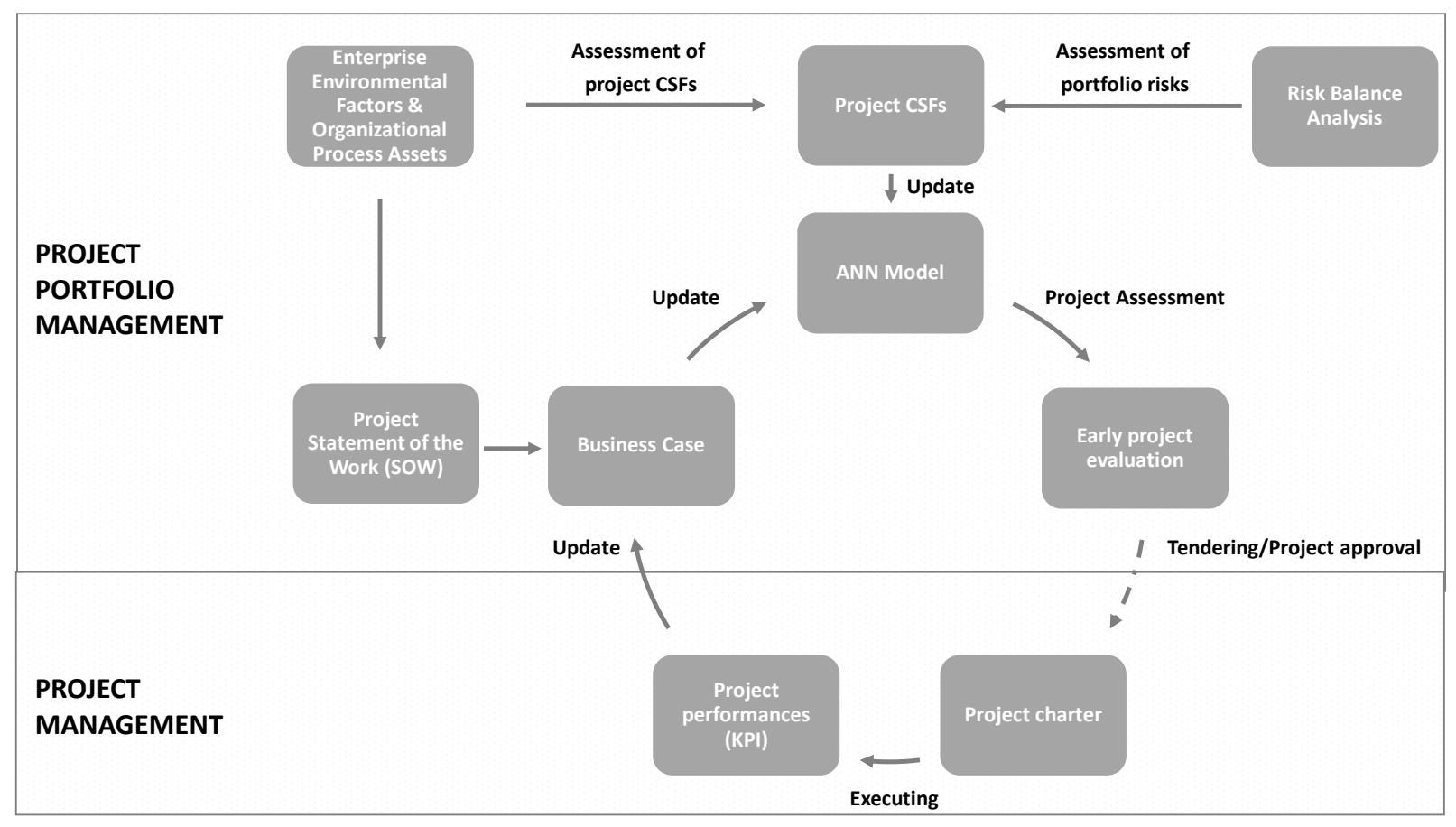

Figure 6. Framework for balancing project and portfolio risks using an ANN model (Source: adapted from Costantino, Di Gravio and Nonino, 2015)

In this first learning process, portfolio managers can express their judgment for a new project on a PCSFs' questionnaire (see for instance the PIP model reported in the first section) to provide the vector of inputs while the neural network gives as output an estimated degree of success, based on previous knowledge stored in its nodes and on the information coming from the business case. If the response is adequate, project fits the company's project portfolio strategy in terms of relevance and of a "standard" level of risk. If the response is not adequate (low degree of success), managers can modify the project characteristics related to the PCSFs or accept and higher level of risk. The model supports the simulation of interventions, testing one or more PCSFs, in both positive and negative way, to evaluate different project scenarios and the impact of improvements before their implementation.

If the company's management approves the project and it advances to initiating phase, the project sponsor and/or the project manager will prepare the project charter, which serve as the basis for project evaluation. Key performance indicators, basing on the same project CSFs, will evaluate project performances, according to the project portfolio strategy. The final version of business case containing the project assessment, traditionally used to increase company's project knowledge base, will allow the model update (second learning process). Increasing the number of projects in assessment and the feedbacks on the performances enables the re-engineering of the model. Modifying the architecture or replicating the learning process on a bigger amount of data, the capability of classification improves, reducing the number of errors and increasing the level of accuracy.

The ANN assessment model allows the reduction of projects' risk failure by identifying their degree of success according to an early evaluation of PCSFs.

\section{FUTURE DIRECTIONS}

This chapter highlights the strategic importance of project selection and the role of risks and uncertainties in project portfolio management. Recently, Teller et al. (2014) analyzed a sample of 177 project 
portfolios finding that formal risk management at the project level and integration of risk information at the portfolio level together with simultaneous risk management at both levels are positively associated with overall project portfolio success. But what does it mean simultaneous risk management at both levels?

Frameworks and project selection methodologies for balancing project portfolio risks, proposed in literature and adopted by companies, consider the two levels in a separate way. Researches on usable methodologies which integrate of project risk management at project and portfolio levels are still far from effective solutions.

Most advanced techniques for project selection using multi-criteria scores are not widely used because too complex as they require too much data and very specific expertise. Moreover, they fail to recognize strategic interrelationships and interrelated resources and objectives among projects.

Finally, majority of project selection models don't provide an adequate treatment of uncertainties. Uncertainty management is closer to the concept of strategy as it regards the management of variability of the inputs to project portfolio activities, but risk management does not cover the complete spectrum addressed by this perspective.

The framework proposed in the chapter uses an artificial neural network scalable to any set of project critical success factors, classifies the level of project's riskiness by extracting the experience of project managers from a set of past successful and unsuccessful projects taking into account risks and uncertainties. The model is one of few attempts of balancing project portfolio by integrating project and portfolio levels during the selection phase on the basis of the analysis of both risks and uncertainties; but there is still much work to do to overcome managers' reluctance in adopting complex portfolio frameworks demonstrating their real effectiveness.

\section{REFERENCES}

Abbasianjahromi, H, \& Rajaie, H. (2012). Developing a project portfolio selection model for contractor firms considering the risk factor. Journal of Civil Engineering \& Management, 18(6), 879-889.

Archer, N. P., \& Ghasemzadeh, F. (1999). An integrated framework for project portfolio selection. International Journal of Project Management, 17(4), 207-216.

Bardhan, I., Bagchi, S., \& Sougstad, R. (2004). Prioritizing a portfolio of information technology investment projects. Journal of Management Information Systems, 21(2), 33-60.

Bardhan, I.R., Kauffman, R.J., \& Naranpanawe, S. (2010). IT project portfolio optimization: A risk management approach to software development governance. IBM Journal of Research and Development, 54(2), paper 2.

Cagno, E., Caron, F., \& Mancini, M. (2007). A Multi-Dimensional Analysis of Major Risks in Complex Projects. Risk Management, 9, 1-18.

Cooper, R.G. (1993). Winning At New Products. Reading: Addison-Wesley, MA.

Cooper, R.G., Edgett, S.J, \& Kleinschmidt, E.J (2001). Portfolio management for new product development: Results of an industry practices study. $R \& D$ Management, 31, 361-380.

Cooper, R.G., Edgett, S.J., \& Kleinschmidt, E.J. (2002). Portfolio management: fundamental to new product success. The PDMA ToolBook 1 for New Product Development, 9, 331-364.

Cooper, R.G., Edgett, S.J., \& Kleinshmidt, E.J. (1997). Portfolio Management for New Products. McMaster University: Hamilton, ON. 
Costantino, F., Di Gravio, G., \& Nonino, F. (2015). Project selection in project portfolio management: An artificial neural network model based on critical success factors. International Journal of Project Management, 33(8), 1744-1754.

Day, G.S. (2007). Is it real? Can we win? Is it worth doing? Harvard Business Review, December, 110120.

Eilat, H., Golany, B., \& Shtub, A. (2006). Constructing and valuating Balanced Portfolios of R\&D Projects with Interactions: A DEA Based Methodology. European Journal of Operational Research, 172(3), 1018-1039.

Floricel, S., \& Ibanescu, M. (2008). Using R\&D portfolio management to deal with dynamic risk. $R \& D$ Management, 38(5), 452-467.

Ghapanchi, A.H., Tavana, M., \& Khakbaz, M.H., Low, G. (2012). A methodology for selecting portfolios of projects with interactions and under uncertainty. International Journal of Project Management, 30, 791-803.

Ghasemzadeh, F., \& Archer, N.P. (2000). Project portfolio selection through decision support. Decision Support Systems, 29, 73-88.

Ghosh, S., \& Jintanapakanont, J. (2004). Identifying and assessing the critical risk factors in an underground rail project in Thailand: a factor analysis approach. International Journal of Project Management, 22(8), 633-643.

Hall, N.G. Long, D.Z. Qi, J., \& Sim, M. (2015). Managing Underperformance Risk in Project Portfolio Selection. Operations Research, 63(3), 660-675.

Hax, A.C. Majluf, N.S. (1983). The use of the industry attractiveness - business strength matrix in strategic planning, Interfaces, 13(2), 54-71.

Huang, X. (2008). Mean-variance model for fuzzy capital budgeting. Computers \& Industrial Engineering, 55, 34-47.

Huang, X. (2010). Portfolio Analysis: From Probabilistic to Credibilistic and Uncertain Approaches. Berlin: Springer-Verlag.

Huang, X. (2011). Mean-risk model for uncertain portfolio selection. Fuzzy Optimization and Decision Making, 10, 71-89.

Huang, X. (2012). A risk index model for portfolio selection with returns subject to experts' estimations. Fuzzy Optimization and Decision Making, 11, 451-463.

Huang, X., \& Qiao, L. (2012). A risk index model for multi-period uncertain portfolio selection. Information Sciences, 217, 108-116.

Huang, X., \& Ying, H. (2013). Risk index based models for portfolio adjusting problem with returns subject to experts' evaluations. Economic Modelling. 30, 61-66.

Jafarizadeh, B., \& Ramazani Khorshid-Doust, R. (2008). A method of project selection based on capital asset pricing theories in a framework of mean-semideviation behavior. International Journal of Project Management, 26, 612-619.

Kaiser, M.G., El Arbi, F., \& Ahlemann, F. (2015). Successful project portfolio management beyond project selection techniques: Understanding the role of structural alignment. International Journal of Project Management, 33, 126-139.

Kloppenborg, T. J., \& Laning, L.J. (2012). Strategic Leadership of Portfolio and Project Management. New York: Business Expert Press. 
Lin, C., Hsieh, P.-J., (2004). A fuzzy decision support system for strategic portfolio management. Decision Support Systems, 38, 383-398.

Meredith, J.R., Mantel, S.J. \& Shafer, S.M. (2015). Project Management: A Managerial Approach, Ninth Edition. Hoboken, NJ: John Wiley \& Sons.

Moustafaev, J. (2010). Delivering exceptional project results: A practical guide to project selection, scoping, estimation and management. J. Ross Publishing.

Nagji, B., \& Tuff, G. (2012). Managing Your Innovation Portfolio. Harvard Business Review, 3(4), 1-5.

Olanrewaju, O.A., Jimoh, A.A., \& Kholopane, P.A. (2011). Comparison between regression analysis and artificial neural network in project selection. In: IEEE International Conference on Industrial Engineering and Engineering Management (pp. 738-741).

Petit, Y. (2012). Project portfolios in dynamic environments: Organizing for uncertainty. International Journal of Project Management, 30(5), 539-553.

Pinto, J.K. (1988). Variations in Critical Success Factors Over the Stages in the Project Life Cycle. Journal of Management, 14(1), 5-18.

Pinto, J.K. (1990). Project Implementation Profile: a tool to aid project tracking and control. International Journal of Project Management, 8(3), 173-182.

Remenyi, D., \& Heafield, A. (1996). Business process re-engineering: some aspects of how to evaluate and manage the risk exposure. International Journal of Project Management, 14(6), 349-357.

Sanchez, H., Robert, B., \& Pellerin, R. (2008). A project portfolio risk-opportunity identification framework. Project Management Journal, 39(3), 97-109.

Schniederjans, M., \& Santhanam, R. (1993). A multi-objective constrained resource information system project selection method. European Journal of Operational Research, 70, 244-253.

Slevin, D.P., \& Pinto, J.K. (1986). The Project Implementation Profile: new tool for project managers. Project Management Journal, 18(4), 57-71.

Söderlund, J. (2004). Building theories of project management: Past research, questions for the future. International Journal of Project Management, 22(3), 183-191.

Teller, J., Kock, A., \& Gemünden H.G. (2014). Risk Management in Project Portfolios Is More Than Managing Project Risks: A Contingency Perspective on Risk Management. Project Management Journal, 45(4), 67-80.

Turner, J.R., \& Müller, R. (2005). The project manager's leadership style as a success factor on projects: a literature review. Project Management Journal, 36, 49-61. 